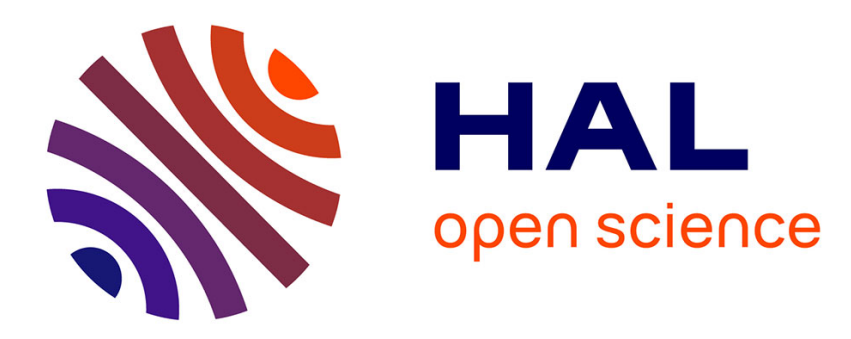

\title{
A study of specimen thickness effects in the impact tests on polymers by numeric simulations
}

\author{
Han Zhao
}

\section{To cite this version:}

Han Zhao. A study of specimen thickness effects in the impact tests on polymers by numeric simulations. Polymer, 1998, 39, pp.1103-1106. 10.1016/S0032-3861(97)00374-1 . hal-00111610

\author{
HAL Id: hal-00111610 \\ https://hal.science/hal-00111610
}

Submitted on 22 Jun 2018

HAL is a multi-disciplinary open access archive for the deposit and dissemination of scientific research documents, whether they are published or not. The documents may come from teaching and research institutions in France or abroad, or from public or private research centers.
L'archive ouverte pluridisciplinaire HAL, est destinée au dépôt et à la diffusion de documents scientifiques de niveau recherche, publiés ou non, émanant des établissements d'enseignement et de recherche français ou étrangers, des laboratoires publics ou privés. 


\title{
A study of specimen thickness effects in the impact tests on polymers by numeric simulations
}

\author{
Han Zhao \\ Laboratoire de Mécanique des Solides, Ecole Polytechnique, 91128 Palaiseau, France
}

\begin{abstract}
Experimental data of polymer behaviour at high strain rates in the literature, mostly obtained with a split Hopkinson pressure bar (SHPB), shows a dependence on the thickness of the specimen. This paper investigates this so-called thickness effect and tries to clarify the doubts on the equilibrium assumption in SHPB tests on polymers by numerical simulations. Fictitious specimens of different thickness with rate sensitive polymer-like constitutive model (Eyring's model) are used to simulate basic data of SHPB tests. The comparison between the given behaviours and those derived from the simulated tests provides an objective appreciation of the quality of tests on polymers (with thin or thick specimen). Results of the simulation prove that the equilibrium assumptions can still be safely used in the case of tests on polymers, and indicate that the thickness effect is mainly due to the radial inertia and friction considerations.
\end{abstract}

\section{INTRODUCTION}

The mechanical behaviour of polymers at high strain rates is often involved in safety studies of engineering applications. For example, in the domain of pipelines for the distribution of fuel gas, the catastrophic failure of the polymeric pipes by a very fast crack propagation, even rare, has been observed under accidental impacts ${ }^{1}$. Recent analyses of tests on real scale pipes allow for the establishment of an empirical critical pressure for the initiation of crack propagation. However, to obtain a theoretical criterion or to perform a numerical simulation, the constitutive law of the materials, of which the pipes are made, is indispensable ${ }^{2,3}$.

A few experimental data of the polymeric behaviour at high strain rates have been reported in the literature, obtained with a split Hopkinson pressure bar (SHPB). Some authors ${ }^{4,5}$ used a very thin specimen $(<2 \mathrm{~mm})$ and gave a quasi-linear relation between the yield stress with the logarithm of the strain rate so that Eyring's model ${ }^{6}$ (see also Section 2.2) is still valid at high strain rates. By contrast, the others $^{7,8}$ used a thicker specimen and found that there is a sharp increase in the yield stress at high strain rates. Such a so-called thickness effect is observed for many polymeric materials.

Recently, Dioh and co-workers ${ }^{9}$ have systematically investigated this thickness effect and used specimens of different thickness $(1.5 \mathrm{~mm}$ and $4.4 \mathrm{~mm})$ but of exactly the same materials. For all the materials studied, such as medium density polyethylene (MDPE), high density polyethylene (HDPE), polycarbonate (PC), and poly(ether ether ketone) PEEK, tests on specimens of different thickness do lead to different rate sensitivities. Results are schematically re-drawn in Figure $l$ where a sharp increase is found for tests on thick specimens.

Such results suggest not only that there exists some experimental imprecision in the classical SHPB analysis where simplifying assumptions are made, but also that one of experimental data and the corresponding behaviour modelling (why not both two), is not accurate. Dioh and co-workers ${ }^{10}$ supposed that the sharp increase observed using thick specimen is not a physical feature but an experimental imprecision which could be probably explained by the wave propagation effects (see Section 2 ) involved in the SHPB tests.

It is then of interest to examine the SHPB testing process in order to know if the classical SHPB analysis leads to acceptable results in the case of tests on polymers and to find which assumption leads to this thickness effect. For this purpose, this paper presents a numeric simulation of SHPB testing process and the author believes that it is a reliable way to appreciate objectively the two kinds of results obtained from specimens of different thickness. The basic SHPB testing data is simulated for fictitious specimens of different thickness, the rate sensitive behaviour of which is described by Eyring's model. Using the classical equilibrium assumption, the average stress-strain curve of the fictitious specimen can be calculated from those simulated basic data. The quality of the measurement in both cases (thin or thick specimen) can be then estimated by the comparison between the given and the recovered material behaviour. In addition, such a simulation allows also for an appreciation of the equilibrium assumption in SHPB tests on polymers.

\section{SIMULATION OF SHPB TESTS ON POLYMER}

\section{Split Hopkinson pressure bar tests and its assumptions}

The SHPB ${ }^{1 !}$, or Kolsky's apparatus ${ }^{12}$ is a standard experimental technique in the study of the constitutive law of materials at high strain rates. A typical SHPB set-up is composed of the long input and output bars with a short specimen placed between them. The impact of the projectile 


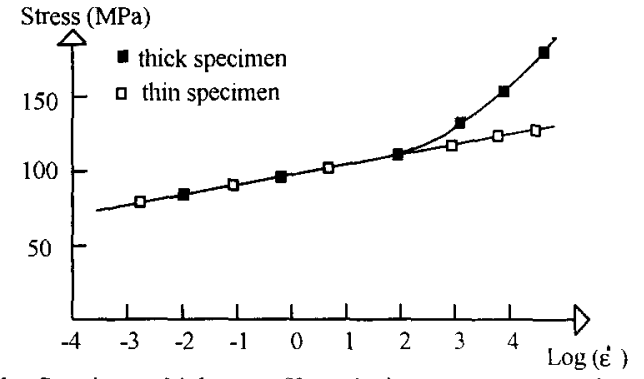

Figure 1 Specimen thickness effects in impact tests on polymers (after Dioh and co-workers)
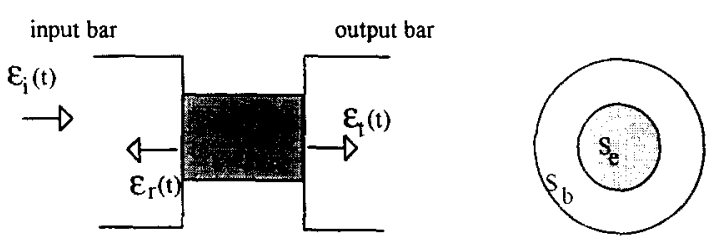

Figure 2 Scheme of classical SHPB analysis

at the free end of the input bar develops a compressive longitudinal incident wave $\varepsilon_{i}(t)$. Once it arrives at the bar specimen interface, a reflected wave $\varepsilon_{\mathrm{r}}(t)$ is developed in the input bar, whereas a transmitted wave $\varepsilon_{\mathrm{t}}(t)$ is developed in the output bar (Figure 2).

From those basic experimental data (incident, reflected and transmitted waves), the classical analysis assumes homogeneous stress and strain fields in the specimen, and an average strain and an average stress are then given by equation (1).

$$
\begin{aligned}
& \dot{\varepsilon}_{\mathrm{s}}(t)=\frac{2 C_{0}}{l_{\mathrm{s}}} \varepsilon_{\mathrm{r}}(t) \\
& \sigma_{\mathrm{s}}(t)=\frac{E_{\mathrm{b}} S_{\mathrm{b}}}{S_{\mathrm{s}}} \varepsilon_{\mathrm{t}}(t)
\end{aligned}
$$

where $l_{\mathrm{s}}$ and $S_{\mathrm{s}}$ are the length and the cross-sectional area of the specimen, whereas $E_{\mathrm{b}}, S_{\mathrm{b}}$ and $C_{0}$ denote Young's modulus, cross-sectional area and wave speed of the bar.

Nevertheless, equation (1) is correct only when the stress and strain fields in the specimen are effectively homogeneous, and this is never true because of wave propagation effects in the specimen. For example, when the input side of the specimen is loaded, the output side remains at rest until the wave goes through the specimen. Such an effect is obviously more important for a thick specimen. However, theoretical ${ }^{13}$, experimental ${ }^{14}$ and numerical ${ }^{15}$ investigations have shown that the equilibrium assumptions, even approximate, do not introduce significant errors in the case of tests on metals. By contrast, for material such as polymeric foam, concrete, rocks, etc., where homogeneous stress and strain fields cannot be assumed, only an identification technique based on an inverse calculation method is theoretically correct ${ }^{16}$.

Furthermore, equation (1) is a one-dimensional analysis and it implies that the three-dimensional effects such as the radial inertia and the friction between the specimen and bars could be neglected. Such an assumption is less convincing when the specimen is a very thin disc. Corrections have been proposed and a smart diameter/thickness ratio $d / l_{\mathrm{s}}$ for the specimen is suggested to limit those effects ${ }^{17,18}$. One interesting study by Gorham ${ }^{19}$ shows that the sharp rise in rate sensitivity of metallic materials would be related to those points.

Even those aspects are not yet well studied in the case of polymers, one can imagine that the general trend remains the same. The three-dimensional effect is important for a thin specimen, whereas the wave propagation effect will be strong for a thick one, and the thickness effects can be explained by one of those assumptions, provided that the signal processing is correctly made ${ }^{20,21}$.

Transient simulations of a split Hopkinson pressure bar with a polymeric-like constitutive law

A complete simulation of the SHPB test will be a threedimensional one which takes into account those two assumptions mentioned above. However, the onedimensional simulation is chosen here. Indeed, the exact three-dimensional boundary condition at bar-specimen interfaces during the test cannot be known, and a threedimensional simulation (with elasto-plastic model) given by Bertholf and Karnes ${ }^{15}$ has shown that the friction and radial inertia hardly interfere with the wave propagation effect. The last can, therefore, be studied separately.

Another practical reason is that there is no possibility in available dynamic FEM codes to introduce a suitable ratesensitive constitutive law for polymers and to deal accurately with the special contact condition of SHPB ${ }^{22}$. This is why a one-dimensional transient numerical simulation is developed here.

The one-dimensional governing equations and the constitutive law are written as follows:

$$
\begin{gathered}
\frac{\partial \sigma(x, t)}{\partial x}=\rho \frac{\partial v(x, t)}{\partial t} \\
\frac{\partial \varepsilon(x, t)}{\partial t}=\frac{\partial v(x, t)}{\partial x}
\end{gathered}
$$

$$
f(\sigma, \varepsilon, \dot{\sigma}, \dot{\varepsilon}, \ldots)=0
$$

where $\sigma, \varepsilon, v$ are the stress, the strain and the particle velocity in the specimen. $\rho$ is the mass density.

The boundary conditions at the two faces of the specimen are given as follows:

$$
\begin{gathered}
\sigma(x, t)-\frac{E_{\mathrm{b}} S_{\mathrm{b}}}{C_{0} S_{\mathrm{S}}} v(x, t)=2 \frac{S_{\mathrm{b}}}{S_{\mathrm{S}}} E_{\mathrm{B}} \varepsilon_{\mathrm{i}}(t) \text { at the input side } \\
\sigma(x, t)+\frac{E_{\mathrm{b}} S_{\mathrm{b}}}{C_{0} S_{\mathrm{S}}} v(x, t)=0 \text { at the output side }
\end{gathered}
$$

The quality of the conclusion derived from the simulated tests depends on how well the constitutive law used in those simulations describes the reality. On the basis of the thermally activated mechanism, Eyring ${ }^{6}$ has proposed a model describing the yield stress $\sigma_{\mathrm{y}}$ as a function of strain rate and temperature (equation (4)).

$$
\frac{\sigma_{\mathrm{y}}}{T}=A\left[\ln \left(\frac{\dot{\varepsilon}}{\dot{\varepsilon}_{0}}\right)+\frac{Q}{R T}\right] \text { or } \dot{\varepsilon}=\dot{\varepsilon}_{0} \exp \left(\frac{\sigma_{\mathrm{y}}}{T A}-\frac{Q}{R T}\right)
$$

where $A, Q, R$ are constant coefficients, amd $T$ is the absolute temperature.

It describes rather accurately the rate sensitivity of polymer at low and medium strain rate $4,5,7-9$, and one of the aims in the study on thickness effects in the literature 
has been to indicate whether Eyring's model is still valid at high strain rates. It is then interesting to consider such a model in our simulations.

\section{Numerical scheme with the method of characteristics}

An elastic-plastic model with rate sensitivity of yield stress described by Eyring's model can be constructed and expressed in the form of a Sokolovsky-Malvern type $\mathrm{e}^{23,24}$ (equation (5)).

$$
\begin{gathered}
\dot{\sigma}=E \dot{\varepsilon}_{\mathrm{el}} \text { if } \sigma \leq \sigma_{0} \\
\dot{\sigma}=E\left(\dot{\varepsilon}_{\mathrm{el}}+\dot{\varepsilon}_{\text {inel }}\right) \text { if } \sigma>\sigma_{0}
\end{gathered}
$$

where $\sigma_{0}$ is the quasi-static yield stress.

Using the Eyring model (equation (4)) to describe the non-elastic part, we have

$$
\dot{\varepsilon}_{\text {inel }}=\dot{\varepsilon}_{0} \exp \left(\frac{\sigma}{\sigma_{0}+B(\varepsilon-\sigma / E)^{n}}-1\right)
$$

The numeric problem defined by the governing equation (equation (2)) and the above constitutive law can be resolved easily by the method of characteristics, because the characteristic network is composed of families of straight lines in this case. The three families of characteristic lines and the characteristic relation that must be satisfied along those lines are defined ${ }^{25}$ in equation (7).

$$
\begin{gathered}
\text { (i) } \frac{\mathrm{d} x}{\mathrm{~d} t}=C_{0} \quad \mathrm{~d} \sigma=-\rho C_{0} \mathrm{~d} v-\rho C_{0}^{2} \dot{\varepsilon}_{\text {inel }} \mathrm{d} t \\
\text { (ii) } \frac{\mathrm{d} x}{\mathrm{~d} t}=-C_{0} \quad \mathrm{~d} \sigma=\rho C_{0} \mathrm{~d} v-\rho C_{0}^{2} \dot{\varepsilon}_{\text {inel }} \mathrm{d} t \\
\text { (iii) } \mathrm{d} x=0 \quad \mathrm{~d} \varepsilon_{\text {inel }}=\dot{\varepsilon}_{\text {inel }} \mathrm{d} t
\end{gathered}
$$

Using a regular discretization grid, the governing equations (equation (7)) with the boundary conditions (equation (4)) are numerically integrated.

\section{TESTS AND THEIR SIMULATIONS}

In order to show the accuracy of the numerical simulation and the describing quality of this model, a set of real SHPB tests on PC at a high strain rate is performed and served as the basis for the comparison test-simulation.

Using the real measured incident wave as input data, the reflected and transmitted waves can be calculated for a fictitious specimen which has the same size as the real one and has the mechanical behaviour described by the model presented above with identified parameters. Figure 3 shows basic measured waves for a test at a strain rate of about $280 \mathrm{~s}^{-1}$ (specimen of PC, diameter $10 \mathrm{~mm}$, length $10 \mathrm{~mm}$ ), compared with the simulated ones. They are very close, and it proves the confidence of the numerical accuracy. Figure 4 shows a comparison (for a set of tests from $230 \mathrm{~s}^{-1}$ to $1650 \mathrm{~s}^{-1}$, specimen of $\mathrm{PC}$, diameter $10 \mathrm{~mm}$, length $10 \mathrm{~mm}$ ) between the stress-strain curves calculated from real measured waves (bold lines) and those from the simulated waves. The describing quality of the model is quite acceptable.

Furthermore, the stress-strain curves calculated from the simulated tests are also very close to the given model at corresponding strain rates. It suggests that the equilibrium

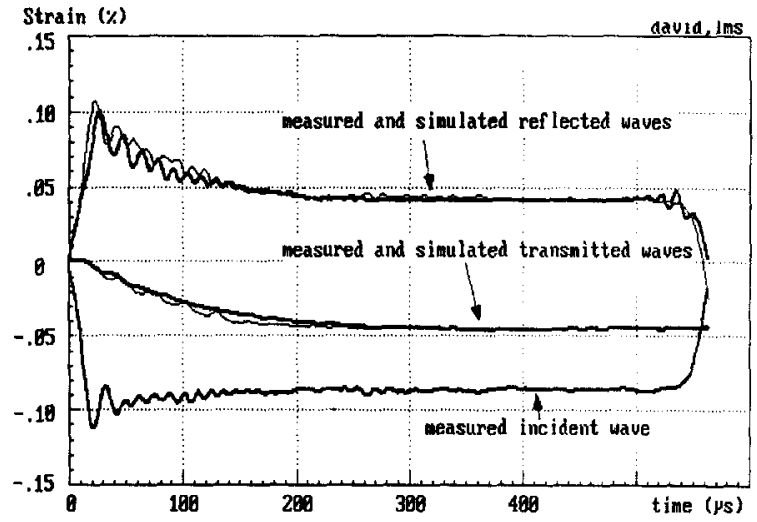

Figure 3 Simulated basic waves of a test on $\mathrm{PC}$, compared with real measured waves

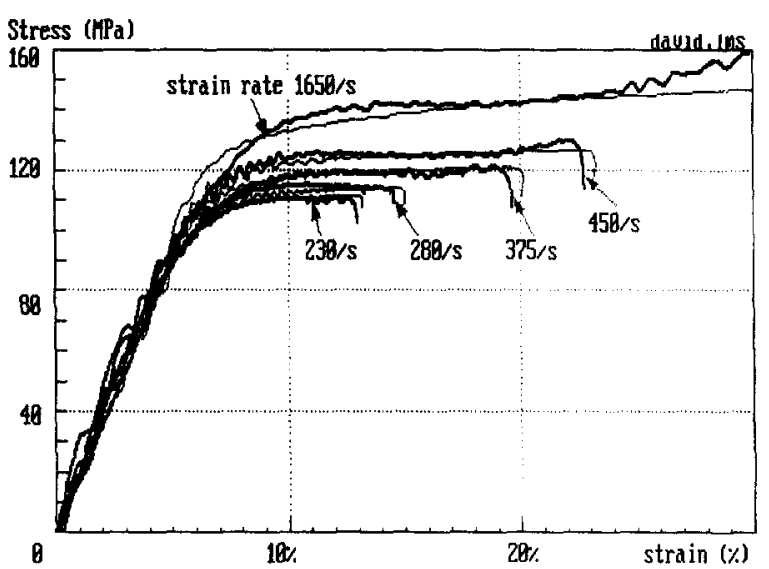

Figure 4 Comparison between stress-strain curves derived from real tests and those from simulated tests

assumption is still valid in the case of tests on polymers. It is noted that those real tests (Figure 4) are just the illustrations of the pertinence of the rate sensitive model used for simulations. This constitutive model is not limited in this range of strain rates. Simulations for tests at higher strain rates (up to $10^{4} \mathrm{~s}^{-1}$, cf. Dioh et al. ${ }^{9}$ ) lead to similar conclusions.

\section{DISCUSSION ON THICKNESS EFFECTS}

The confidence on the simulation and on the model allows, therefore, for an objective examination of the thickness effect. Fictitious tests are then simulated for a $15.8 \mathrm{~mm}$ aluminium SHPB set-up, as used by Dioh and co-workers ${ }^{9}$, where the thickness effects are experimentally proved. The used incident wave lasts $450 \mu \mathrm{s}$ with a rising time of $15 \mu \mathrm{s}$, which corresponds to a real SHPB incident time. Tests on PC with two types of specimen (diameter $12.7 \mathrm{~mm}$, thickness 1.5 and $4.4 \mathrm{~mm}$, as used by Dioh and co-workers ${ }^{9}$ ) are simulated at several impact velocities (the strain rates range is from $10^{2} \mathrm{~s}^{-1}$ to $10^{4} \mathrm{~s}^{-1}$ ). It is noted that the rising time and specimen/bar impedance ratio also have their effects on the equilibrium process in the specimen. The choice of a constant rising time (experimental observation in our tests shows very little variation) and of the same diameter for two kinds of specimen in this simulation is motivated by those considerations.

The stress-strain curves are calculated from simulated basic waves, using classical SHPB analysis. Figure 5 shows the rate sensitivities of the flow stress (at a strain of 10\%) derived from those two sets of simulated tests, compared with the given rate sensitivity. There is then no apparent 


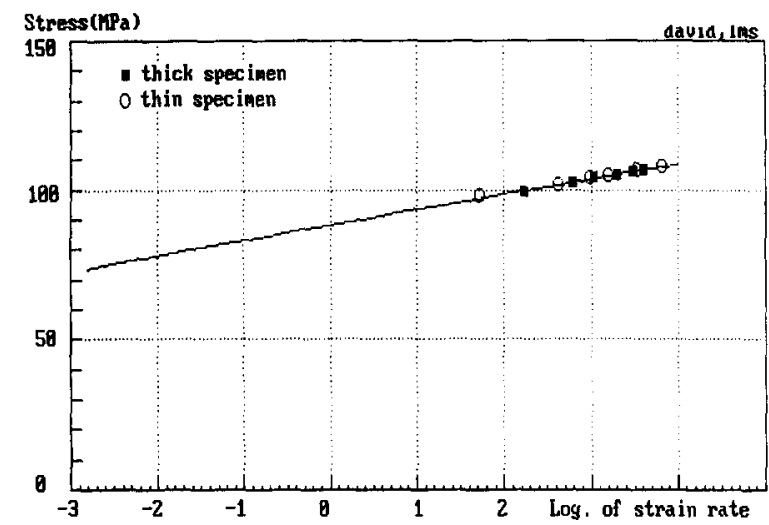

Figure 5 Rate sensitivity obtained from simulated tests on specimens of different thickness, compared with the given rate sensitivity

thickness effect for the simulated tests, and it is in contrast to the known simulation works given by Dioh et al. ${ }^{10,26}$. The explanation may be related, in the author's opinion, to the use of the simple elastic-plastic bilinear constitutive law in their simulation.

Certainly, the simulation here is not a complete one. The chosen behaviour may not describe all the mechanical feature of polymers and the wave propagation effect could strongly interfere with the three-dimensional effect in the case of polymers. It must be also noted that there will never be a really complete simulation of experiments (because the contact condition is unknown, as is the real behaviour of polymers). The simulation presented here proves at least that the equilibrium assumption does not introduce significant errors and there is no thickness effect when the present rate-sensitive constitutive law, which is probably quite close to reality, is used. This result suggests then that the thickness effect is not due to wave propagation effects in the specimen and is mainly due to the three-dimensional effect, and it gives, hopefully, a reliable indication for further research into the thickness effect.

\section{CONCLUSION}

A simulation of SHPB tests on polymers is performed to investigate the specimen thickness effects observed in experimental data reported in the literature. A rate sensitive (Eyring's model) polymer-like constitutive relation is used in this simulation which is performed by the method of characteristics. It is concluded that the equilibrium assumption is still valid for this type of constitutive law. It can be then a priori safely used in the case of tests on many polymers. It is also shown that there are no thickness effects in the simulated tests. It may suggest that the thickness effect is mainly related to the three-dimensional effects in the SHPB test.

\section{REFERENCES}

1. Greig, J. M., Leevers, P. S. and Yayla, P., Eng. Fracture Mech., $1992,42,663$.

2. Kanninen, M. F., Int. J. Fracture Mech., 1970, 6, 94.

3. Yayla, P. and Leevers, P. S., Eng. Fracture Mech., 1992, 42, 675.

4. Briscoe, B. J. and Nosker, R. W., Polym. Commun., 1985, 26, 307.

5. Walley, S. M., Field, J. E., Pope, P. H. and Safford, N. A., J. Phys. III, 1991, 1, 1889.

6. Eyring, H., J. Chem. Phys., 1936, 4, 283.

7. Rietsch, F. and Bouette, B., Eur. Polym. J., 1990, 26, 1071.

8. Chou, S. C., Robertson, K. D. and Rainey, J. H., Exp. Mech., 1973. 13,422 .

9. Dioh, N. N., Leevers, P. S. and Willams, J. G., Polymer, 1993, 34 4230.

10. Dioh, N. N., Ivankovic, A., Leevers, P. S. and Willams, J. G., $J$ Phys. III, 1994, 4, 119.

11. Hopkinson, B., Phil. Trans. Roy. Soc, 1914, A213, 437.

12. Kolsky H., Stress Waves in Solids. Clarendon Press, Oxford, 1963.

13. Jahsman, W. E., J. Appl. Mech., 1971, 38, 77.

14. Bell, J. F., J. Mech. Phys. Solids, 1966, 14, 309

15. Bertholf, L. D. and Karnes, J., J. Mech. Phys. Solids, 1975, 23, 1

16. Zhao, H. and Gary, G., Int. J. Solids \& Structures, 1996, 33, 3363.

17. Davies, E. D. H. and Hunter, S. C., J. Mech. Phys. Solids, 1963, 11 155.

18. Malinowski, J. Z. and Klepaczko, J. R., Int. J. Mech. Sci., 1986, 28 381 .

19. Gorham, D. A., J Phys. IV (France), 1991, 1, 411

20. Davies, R. M., Phil. Trans. Roy. Soc, 1948, A240, 375

21. Zhao, H. and Gary, G., J. Mech. Phys. Solids, 1995, 43, 1335.

22. Zukas, J. A., High Velocity Impact Dynamics. John Wiley, New York, 1990.

23. Sokolovsky, V. V., Prikl. Mat. Mekh., 1948, 12, 261

24. Malvern, L. E.. J. Appl. Mech., 1951, 18, 203.

25. Cristescu, N., Dynamic Plasticity. North-Holland, Amsterdam 1967.

26. Dioh, N. N., Ivankovic, A., Leevers, P. S. and Willams, J. G., Proc R. Soc. Lond. A, 1995, 449, 187. 